Saudi Journal of Biomedical Research

Abbreviated Key Title: Saudi J Biomed Res ISSN 2518-3214 (Print) |ISSN 2518-3222 (Online)

\title{
Prevalence of Trypanosoma Evansi (Surra) Infection in Horses and Donkeys in Attock Region of Punjab, Pakistan
}

\author{
Syed Saad ul Hassan Bukhari ${ }^{1 *}$, Muhammad Asif Rafiq ${ }^{2}$, Usman Ghani \\ ${ }^{1}$ Saeed Veterinary Medical Clinic, Attock, 43600, Pakistan \\ ${ }^{2}$ Department of Biochemistry, University of Agriculture, Faisalabad, 38000, Pakistan
}

DOI: 10.36348/sjbr.2019.v04i11.006

| Received: 14.11.2019 | Accepted: 21.11.2019 | Published: 22.11 .2019

*Corresponding author: Syed Saad ul Hassan Bukhari

\section{Abstract}

A clinical study has been carried out (from July to September, 2019) in order to determine the prevalence of Trypanosoma evansi infection in horses and donkeys in the Attock region of Punjab-Pakistan. A total of 100 horses (50 stallions and 50 mares) and 100 donkeys (50 jacks and 50 jennets) were examined and $\mathrm{T}$. evansi was searched by the examination of wet blood film and stained thin smears (Giemsa\& field staining).Eleven horses (11\%, three stallions and eight mares) and 9 donkeys (9\%, four jacks and five jennets) were positive respectively. However, further studies and efforts must be done by the society, government and private institutions in order to develop control measures in diseased studs/areas and to avoid dissemination of the disease.

Keywords: Trypanosoma evansi; surra; prevalence; horses; donkey; Attock; Pakistan.

Copyright @ 2019: This is an open-access article distributed under the terms of the Creative Commons Attribution license which permits unrestricted use, distribution, and reproduction in any medium for non-commercial use (NonCommercial, or CC-BY-NC) provided the original author and source are credited.

\section{INTRODUCTION}

Equine trypanosomiasis caused by Trypanosoma evansi (T. evansi) locally known as "surra," is a frequent health issue of horses and donkeys in a wide range of geographical zones in the world. The clinical form of trypanosomiasis is presented as fever, anemia, edema of genitalia \& limbs and petechial hemorrhages in conjunctiva [1]. Chronic infections are manifested by decreased no. of parasites in blood or some in localized body tissues. However, in horses, pathogenic trypanosomes, for example, T. evansi, T. brucei and $\mathrm{T}$. equiperdum are considered to cause surra, nagana and dourine respectively [2]. Horses and donkeys are particularly susceptible to T. evansi \& $\mathrm{T}$. brucei, but natural infections with $\mathrm{T}$. vivax\& $\mathrm{T}$. congolense are rarely seen in horses and donkeys [3]. The play of carrier animal can be emarginated by the facts that severe form of trypanosomiasis occurs in horses and camels, however, buffalo and cattle are considered reservoirs of infection for horses and donkeys. One of the most important factors of this disease is the presence of plentiful vectors in the regions of equine (horses and donkeys) population. As, it is an arthropod-borne infection, and dissemination of this disease is through biting flies such as Lyperosia, Tabanus, Glossina, Stomoxys, and sometimes through other flies, acting as mechanical carrier's [4]. Diagnosis of trypanosomiasis is simply based on the visual examination of the parasites under the microscope in the blood which can be supplemented with biochemical, hematological, molecular and serological tests [5].

The actual specificity and sensitivity of these diagnostic techniques is dependent on the vol. of the blood to be examined and skills \& experience of the researcher [6]. The prevalence and dissemination oftrypanosomiasisvariesgreatlybetweendifferentgeograp hicalregionsbecause of number of different reasons. In Pakistan, studies on trypanosomiasis prevalence have been carried out using different diagnostic techniques in Faisalabad [7, 8] Gujranwala [9] \& North West Frontier Province [10]. The purpose of this clinical study was to analyze the prevalence of $\mathrm{T}$. evansi in horses and donkeys in Attock region of Punjab using wet blood film and stained (Giemsa) smears.

\section{MATERIALS AND METHODS}

A total of 200 equines (50 stallions, 50 jacks, 50 mares and 50 jennets) were randomly selected for present study. These animals belonged to different small holding studs located at various regions of Attock district of Punjab-Pakistan and were locally bred and reared. Blood samples were taken from the jugular vein using vacutainer (3ml) containing EDTA.K3 (BIOVAC). T. evansi was searched by the examination of wet blood film and stained thin smears. 
Wet Blood films were made by placing a drop of blood on one end of a slide and by using a spreader slide to disperse the blood over the slide's length. The aim is to get a region (feathers like), where the cells are spaced far enough apart to be counted and differentiated.

For Giemsa (Giemsa powder $7.6 \mathrm{gm} / \mathrm{L}$, Glycerol $500 \mathrm{ml} / \mathrm{L}$ and Methanol $500 \mathrm{ml} / \mathrm{L}$ ) staining fixation of air dried blood film was done in absolute methanol by dipping film briefly (two dips) in jar containing absolute methanol after that film was air dried and stained with diluted Giemsa stain (1:20, vol/vol). After that film was washed by briefly dipping in jar containing buffered water (two dips). Slide was air dried in vertical position.

For field staining, blood film was air dried first. Fixation was done in absolute methanol by dipping film briefly (three dips). Later, slide was flooded with $1 \mathrm{ml}$ field stain $\mathrm{B}$, diluted 1 in 4 with distilled water. After that slide was flooded with $1 \mathrm{ml}$ field stain A and rinsed with tap water and air dried.

T. evansi was searched by the examination of wet blood film and stained thin smears under light microscope.

\section{RESULTS}

The presence of $\mathrm{T}$. evansi was diagnosed in eleven horses (11\%, three stallions and eight mares) and 9 donkeys (9\%, four jacks and five jennets) were positive respectively.

Table-1: Result summary

\begin{tabular}{|c|c|c|c|}
\hline Animal Name & Total no. & Positive & Negative \\
\hline Stallions & 50 & 3 & 47 \\
\hline Jacks & 50 & 4 & 46 \\
\hline Mares & 50 & 8 & 42 \\
\hline Jennets & 50 & 5 & 45 \\
\hline
\end{tabular}

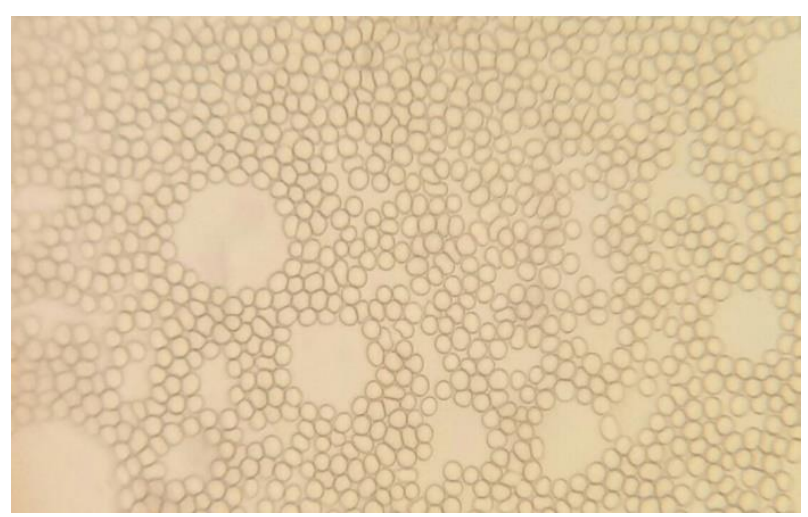

Fig-1: Wet Blood Film (without stain)

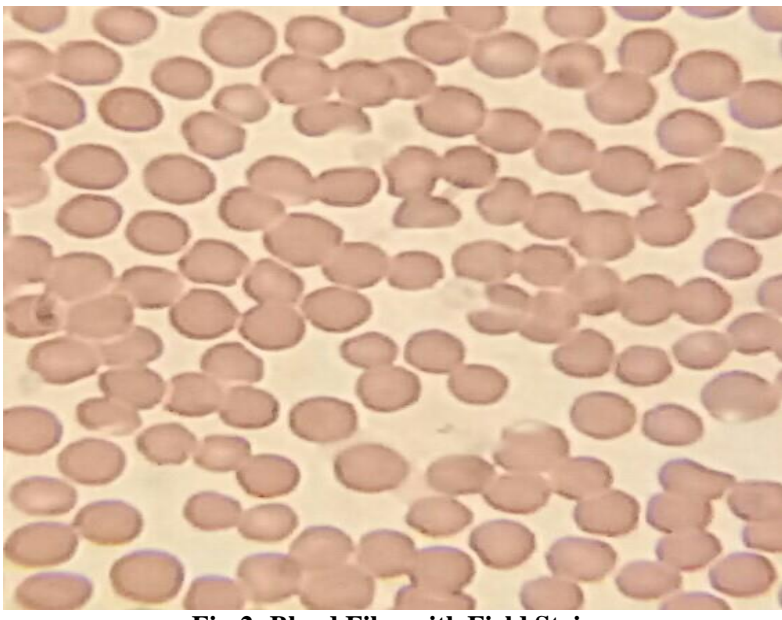

Fig-2: Blood Film with Field Stain

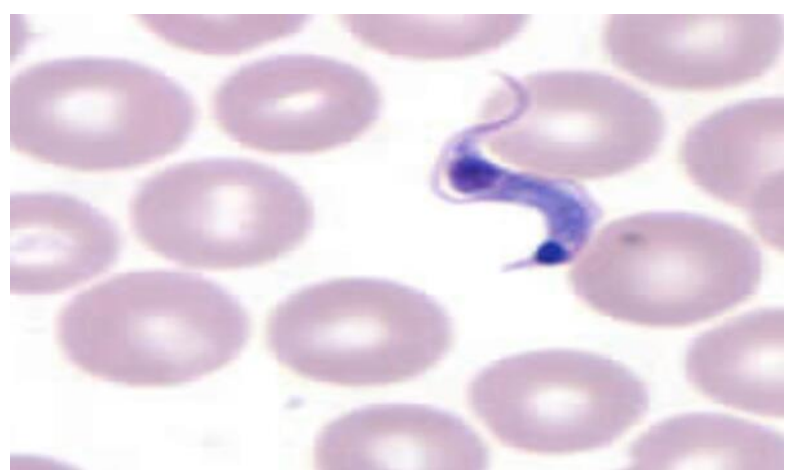

Fig-3: Blood Film with Giemsa Stain (Positive Sample)

\section{DISCUSSION}

Sporadic outbreaks of trypanosomiasis were reported in Pakistan, since identification T. evansi was done for the first time by parasitological methods [11]. However, comprehensive epidemiological study relevant to other trypanosome's in pakistan is lacking. The prevalence of $T$. evansi in Pakistan in equines industry was ranging from 5.2-9.1 \% [12]. Previous studies showed that in different areas of Pakistan, Trypanosoma prevalence in Faisalabad of 5.18\% and $9.09 \%$ in horses and donkeys, respectively [7, 8]. And $3.35 \%$ in horses in Gujranwala [9], $7.41 \%$ in horses in NWFP [10]. Previous examination 100 horses at Lahore (Pakistan) with three different diagnostic methods, direct blood smear gave 5\%, stained slide gave $11 \%$ and indirect hemagglutination method (IHA) gave $13 \%$ positive results of infection [13].The diagnosis of trypanosomes infection remains a challenge, particularly since the parasitemia is often very low in a majority of infections [14]. Microscopy has traditionally been employed in the positive identification of the parasites $[15,16]$.

\section{CONCLUSION}

Trypanosoma evansi has been found Attock district of Punjab Pakistan, showing seasonal variation of its occurrence being higher in rainy season. The distribution of Trypanosoma evansi and prevalence was equally distributed in both donkeys and horses. The absence of Trypanosoma infections in carrier animals 
does not rule out the role of these animals in the transmission of trypanosomes. It is needed to know molecular epidemiology and the species present in the other areas of Pakistan. However, further studies are immensely important to know molecular epidemiology and the species present in the other parts of Pakistan in order to regularize control measures in the infected studs, detection of possible reservoirs, transmitters and to avoid dissemination of the Trypanosomes.

\section{REFERENCES}

1. Elshafie, E. I., Sani, R. A., Sharma, R., \& Abubakar, I. A. (2018). Clinical and Hematological Profiles of Malaysian Ponies Experimentally Infected with a Field Strain of Trypanosoma evansi. The Open Parasitology Journal, 6(1).

2. Claes, F., Agbo, E. C., Radwanska, M., Te-Pas, M. F., Baltz, T., De Waal, D. T., Goddeeris, B. M., Claassen, E., \& Buscher, P. (2003). How does Trypanosoma equiperdum fit into the Trypanozoon group, a cluster analysis by RAPD and multiplex endonuclease genotyping approach. Parasitology, 126, 425-31.

3. Kihurani, D. O., Nantulya, V. M., Mbiuki, S. M., Mogoa, E., Nguhiu-Mwangi, J., \& Mbithi, P.M.F. (1994). Trypanosoma brucei, T. congolense and T. vivax infections in horses on a farm in Kenya. Tropical animal health and production, 26(2), 95-101.

4. Soulsby, E. J. L. (1982). Helminths. Arthropods and Protozoa of domesticated animals, 291.

5. Nantulya, V. M. (1990). Trypanosomiasis in domestic animals: the problems of diagnosis. Revue Scientifique Et Technique Office Internatonal Des Epizooties, 9(2), 357-67.

6. O. I. E. (2000). Manual of Standards for Diagnostic Tests and Vaccines, 3rd Edition, Office International des Epizootics, World Organization for Animal Health, 660-664.

7. Khan, M. Q., Hayat, B., \& Hayat, C. S. (1987). Prevalence of blood parasites in equines in and around Faisalabad [Pakistan]. Pakistan Veterinary Journal (Pakistan).

8. Butt, A. A., Chaudhry, N. I., Muhammad, G., Athar, M., \& Iqbal, K. (1996). Prevalence of haemoparasites among dromedary in and around Faisalabad (Punjab). Journal of Camel Practice and Research, 3(2):103-106.

9. Waheed, M. A., Qureshi G. H., \& Gondal, J. L. (2003). A report on Surra in Gujranwala. Pakistan Veterinary Journal, 23, 170-172.

10. Bano, L., \& Jan, A. H. (1986). Natural occurrence of trypanosomiasis in ungulates of NWFP [Pakistan]. Pakistan Veterinary Journal, 6, 137 139.

11. Lal, H. K. (1947). Geographical and seasonal incidence of surra in Punjab. Indian Journal Veterinary Science, 17, 201-207.

12. Khan, M. Q., Hayat, B., \& Hayat, C. S. (1987). Prevalence of blood parasites in equines in and around Faisalabad [Pakistan]. Pakistan Veterinary Journal (Pakistan).

13. Saeed, K. (1986). Comparative study of IHA test with traditional diagnostic methods for Trypanosoma evansi Infection in Horses. MSc (Hons.) Thesis, College of Veterinary Sciences, Lahore, University of Agriculture, Faisalabad. Sci. 17, 201-207.

14. Masake, R. A., Majiwa, P. A., Moloo, S. K., Makau, J. M., Njuguna, J. T., Maina, M., Kabata, J., \& Nantulya, V. M. (1997). Sensitive and Specific Detection of Trypanosoma vivax Using the Polymerase Chain Reaction. Experimental parasitology, 85(2), 193-205.

15. Murray, M., Murray, P. K., \& McIntyre, W. I. M. (1977). An improved parasitological technique for the diagnosis of African trypanosomiasis. Transactions of the Royal Society of Tropical Medicine and Hygiene, 71(4), 325-326.

16. Woo, P. T. K. (1971). Evaluation of the haematocrit centrifuge and other techniques for the field diagnosis of human trypanosomiasis and filariasis. Acta tropica, 28(3), 298-303. 